Annuaire suisse de politique de développement

13 | 1994

Annuaire Suisse - Tiers Monde 1994

\title{
VIII. Chronologie Suisse et internationale
}

\section{(2) OpenEdition}

1 Journals

Édition électronique

URL : http://journals.openedition.org/aspd/1038

DOI : 10.4000/aspd.1038

ISSN : 1663-9669

Éditeur

Institut de hautes études internationales et du développement

\section{Édition imprimée}

Date de publication : 1 janvier 1994

Pagination : 159-163

ISSN : 1660-5934

\section{Référence électronique}

"VIII. Chronologie Suisse et internationale », Annuaire suisse de politique de développement [En ligne],

13| 1994, mis en ligne le 19 décembre 2012, consulté le 08 septembre 2020. URL : http://

journals.openedition.org/aspd/1038; DOI : https://doi.org/10.4000/aspd.1038 


\section{Chronologie Suisse et internationale}

\section{Septembre 1992}

3 septembre

Conférence annuelle de la DDA sur le thème du développement en Afrique, Berne.

15-18 septembre

Session du Conseil international sur le cacao à Londres.

16 septembre

Ouverture de la procédure de consultation sur la ratification de la Convention des Nations Unies pour les droits de l'enfant du 20.11.1989.

21-30 septembre

Session du Conseil international du café à Londres.

22-24 septembre

Session annuelle du FMl et de la Banque mondiale à Washington. La Suisse

devient formellement membre des deux organisations.

28 septembre-14 octobre

CNUCED, première partie de la 39ème session du Conseil du commerce et du développement, Genève.

\section{Octobre 1992}

9 octobre

Vote final du Parlement sur l'arrêté fédéral sur les coupures linéaires des 16 octobre dépenses de la Confédération pour les années 1993 à 1995.

Journée mondiale de l'alimentation sur le thème "nourriture et alimentation". Diverses actions sont entreprises en Suisse sur les conséquences de la suralimentation au Nord et sur la croissance de la population dans le Sud. 


\section{9-25 octobre}

Semaine d'information pour une Suisse sans fuite de capitaux, organisée par une coalition d'organisations de développement de milieux d'églises et de syndicats, en lien avec la campagne 500 ans d'oppression-500 ans de résistance en Amérique latine.

31 octobre

Réunion à Lausanne sur le thème de la politique d'asile de la Suisse et politique européenne en la matière. Organisé par la le MODS, Mouvement pour une Suisse ouverte, démocratique et solidaire.

\section{Novembre 1992}

\section{2-13 novembre}

CNUCED, 3ème session de la Conférence des Nations Unies sur le cacao, Genève.

18-21 novembre

Symposium "Agriculture et Environnement", Swissaid, WWF, Ligue suisse pour la protection de la nature, Berne.

30 novembre-4 décembre

Première conférence de la Convention de Bâle à Montevideo, Uruguay.

\section{Décembre 1992}

4 décembre

Le Conseil des Etats accepte le crédit complémentaire sur l'aide aux pays de l'Europe centrale et orientale de 600 millions, portant cette aide à 1,4 milliards de francs.

\section{5-11 décembre}

OMS et FAO, Conférence des Nations Unies sur la nutrition, Rome. 8 décembre

Le Service chrétien pour la paix résilie le contrat sur la prise en charge des réfugiés qui le liait à l'Office fédéral des réfugiés, pour protester contre la politique suisse d'asile.

15 décembre

Les représentants de la Banque mondiale et de 34 pays donateurs se mettent d'accord à Berne sur la 10ème reconstitution du capital de l'Agence internationale du développement (AID), d'une valeur de 13 milliards de DTS.

\section{Janvier 1993}

\section{7-24 janvier}

7 ème édition du Festival international de films de Fribourg, suivi du circuit "les films du Sud", dans plusieurs villes suisses. 20 janvier

CNUCED, entrée en vigueur de l'Accord international sur le sucre 


\section{Février 1993}

22 février-5 mars

CNUCED, 4ème session de la Conférence des Nations Unies sur le cacao, Genève.

\section{Mars 1993}

15-26 mars

CNUCED, deuxième partie de la 3èmesession du Conseil du commerce et 29-31 mars du développement, Genève

Réunion des pays de l'OCDE à Madrid sur la migration des pays du Sud et de l'Est vers les pays industrialisés.

31 mars - 3 avril

Rencontres Médias Nord-Sud à Genève, avec le concours de films TV ou de producteurs indépendants sur le thème du développement.

\section{Avril 1993}

13-14 avril

Conférence sur le développement économique en Europe de l'Est, 13-16 avril

\section{Copenhague.}

CNUCED, première session de la Conférence des Nations Unies sur les bois tropicaux, Genève. Négociation d'un nouvel Accord international.

26 avril-1er mai 27 avril

Session de printemps du FMl et de la Banque mondiale, Washington.

Réunion annuelle de la Banque Européenne pour la reconstruction et le 29-30 avril développement, BERD, Londres.

Conférence ministérielle sur l'environnement en l'Europe, avec l'adoption d'un programme d'action pour l'Europe centrale et orientale. Lucerne.

\section{Mai 1993}

3-14 mai 24-28 mai

OMS, 46ème Assemblée mondiale de la santé, Genève.

Premier Sommet des peuples indigènes à Chimaltenango, Guatemala pour préparer la Conférence mondiale sur les droits de l'Homme de Vienne.

Session du comité intergouvernemental pour une Convention contre la désertification, Nairobi 


\section{Juin 1993}

2-22 juin

7 - 11 juin

OIT, 80ème session de la Conférence internationale du travail, Genève.

14-25 juin

9ème conférence mondiale sur le SIDA, Berlin

Nations Unies, Conférence mondiale sur les droits de l'homme, Vienne.

14 - 25 juin

Nations Unies, première session de la Commission du développement durable, instituée dans le cadre du suivi de la Conférence de Rio sur l'environnement et le développement, New York.

19 juin 21-25 juin

Fête des 25 ans de la Déclaration de Berne, Fribourg

CNUCED, 2ème session de la Conférence des Nations Unies sur les bois tropicaux, Genève.

\section{Juillet 1993}

\section{7-8 juillet}

5 - 16 juillet

Sommet économique des 7 pays les plus industrialisés (G-7) à Tokyo.

CNUCED. adoption d'un nouvel Accord international sur le cacao, à l'issue de la 5 ème session de la Conférence sur le cacao.

\section{Août 1993}

30 août-1er septembre

Conférence internationale pour la protection des victimes de la guerre, Genève.

\section{Septembre 1993}

\section{6 septembre}

Conférence annuelle de la DDA à Berne, sur le thème: "Politique du développement des années 90 , dialogue ou ingérence?".

20 septembre-1er octobre

CNUCED, première partie de la 3èmesession du Conseil du commerce et 24 septembre du développement, Genève.

Le Comité d'aide au développement (CAD) de l'OCDE examine la politique de coopération de la Suisse.

Session annuelle du FMl et de la Banque mondiale à Washington. 


\section{Octobre 1993}

\section{4-15 octobre}

CNUCED, 3ème session de la Conférence des Nations Unies sur les bois 15 octobre tropicaux, Genève.

Symposium d'automne de Swissaid sur le thème: "recherche agricole publique au service de l'industrie agroalimentaire ou des besoins des 16 octobre paysans ?" Berne. 18 octobre

Journée mondiale de l'alimentation, sous le thème "la diversité c'est la vie". 20-28 octobre

L'UDC dépose l'initiative "contre l'immigration illégale".

Premières consultations du FMl avec la Suisse sur la politique économique de la Suisse, ceci conformément à l'article IV des statuts du FMI.

\section{Novembre 1993}

\section{5-16 novembre}

CNUCED, 6ème partie de la Conférence des Nations Unies sur le cacao, Genève.

18 novembre

5ème Conférence mondiale sur la protection de la couche d'ozone (Protocole de Montréal).

\section{Décembre 1993}

\section{2 décembre}

Les oeuvres d'entraide et les organisations de protection de l'environnement déclarent la journée des droits de l'homme aussi journée d'action pour le 13 décembre climat.

Le Conseil fédéral ouvre la procédure de consultation sur le projet de nouvelle loi sur le matériel de guerre. Ce projet prévoit un renforcement du contrôle sur les exportations d'armes.

\section{5 décembre}

GATT, conclusion du 8ème cycle négociations multilatérales du GATT 29 décembre (Uruguay Round), après 7 ans.

Nations Unies, entrée en vigueur de la Convention sur la biodiversité, qui traitent de la protection des milieux de vie des espèces vivantes et de l'exploitation économique de leur potentiel génétique. 